\title{
El testeo universal en adultos del virus de la inmunodeficiencia humana y una terapia antimetroviral inmediata podría eliminar su transmisión y reducir costos
}

\author{
Universal voluntary human inmuno-deficciency testing with immediate antiretroviral therapy may eliminate its transmission and save costs
}

\section{Objetivo}

Comparar contra distintas alternativas a largo plazo y en el contexto de una epidemia en población adulta heterosexual, la efectividad y los costos de una estrategia de testeo universal y voluntario del virus de la inmunodeficiencia humana $(\mathrm{VIH})$ junto a un tratamiento antirretroviral (TAR) inmediato.

\section{Diseño, lugar y pacientes}

Sobre una población hipotética de mayores de 15 años basada en la epidemia actual del VIH entre adultos heterosexuales; se aplicó un modelo matemático determinístico* para evaluar la transmisión del VIH, y un modelo estocástico* para explorar los efectos de los parámetros del primero sobre el número de infecciones secundarias. Se simuló una epidemia como la de Sudáfrica y se utilizaron datos de otros países de bajos y medianos ingresos.

\section{Intervención}

Se compararon cuatro alternativas:

1) TAR en personas con VIH y menos de 350 células CD4+ por $\mu \mathrm{L}$; 2) Testeo universal y voluntario del VIH una vez al año más un inmediato TAR en infectados con menos de 350 células CD4+ por $\mu \mathrm{L}$;

3) Testeo universal y voluntario del VIH una vez al año más un inmediato TAR en infectados con menos de 350 células CD4+ por $\mu \mathrm{L}$, más otras estrategias de prevención en adultos;

4) Testeo universal y voluntario del VIH una vez al año más un inmediato TAR en infectados, independientemente del número de células CD4+ por $\mu \mathrm{L}$.

\section{Medición de costos y resultados principales}

Se compararon los costos de las intervenciones contemplando los costos de las drogas de primera y segunda línea e incluyen-
Granich R y col. The Lancet 2009; 373:48-57.

do el costo de su entrega, de las pruebas de laboratorio y del manejo de los casos. Luego, los costos fueron comparados contra el gasto anual que erogó Sudáfrica (17\% del mundial) para la prevención y el tratamiento del VIH hasta 2008 ; y con el $17 \%$ del presupuesto anual global estimado por la agencia UNAIDS para lograr un acceso universal hasta el año 2015.

\section{Resultados principales}

La estrategia propuesta puede acelerar la transición desde la actual fase endémica hacia una fase de eliminación, en la cual todos los adultos diagnosticados por VIH reciban TAR en forma irrestricta. Esta intervención puede reducir la incidencia y la mortalidad por VIH a menos de un caso por cada mil personas en 2016, ó dentro de los diez años desde la implementación completa de la estrategia; así como reducir la prevalencia de VIH a menos del $1 \%$ en 50 años.

Los autores estiman que en 2032 el costo anual -tanto de la estrategia actual como de la "modelada"- sería de 1.700 millones de u\$s. Sin embargo, luego de este período el costo de la estrategia actual continuaría en aumento, mientras que el de la estrategia modelada se reduciría. El modelo encuentra un valor máximo para el financiamiento anual de la intervención propuesta hacia 2015 (u\$s 3.400 millones) siendo menor a la proyección de la UNAIDS (u\$s 8.840 millones).

\section{Conclusiones}

La estrategia de intervención propuesta podría cambiar la actual fase epidémica de la enfermedad a largo plazo.

Fuentes de financiamiento: ninguna.

\section{Comentario}

La Declaración del Milenio ha consolidado un fuerte interés por reducir la incidencia y mortalidad del VIH/SIDA hacia 2015'. En esta empresa, la Organización Mundial de la Salud actúa fortaleciendo la respuesta del sector sanitario mediante distintas acciones, como por ejemplo, la elaboración del presente modelo. A pesar de que la estructura más utilizada para modelizar la epidemia del VIH/SIDA son las ecuaciones diferenciales ordinarias, este modelo sigue una compleja pero no definida estructura de Markov*, quizás más común en enfermedades crónicas. Sin embargo, este esquema no analiza el impacto sobre diferentes cohortes. Por lo tanto y dado que importa reducir el número de infecciones secundarias, y que las intervenciones actuales suelen enfocarse en poblaciones como trabajadoras del sexo; sería interesante que se incorpore la posibilidad de caracterizar estas cohortes, lo que permitiría una comparación más objetiva entre las intervenciones. Además, y entendiendo la importante demanda de insumos requeridos y su escasa disponibilidad, un análisis bajo un enfoque bayesiano* sería probablemente más adecuado.

Finalmente, la limitación más importante y admitida por los propios autores, es el deficiente análisis económico realizado. Sin embargo, teniendo en cuenta la libre disponibilidad de las herramientas para el costeo de intervenciones del programa WHO-CHOICE, es probable que dicha barrera pueda ser rápidamente superada. Es importante destacar que, ante la conmoción que el presente artículo ha generado en la comunidad, se prevé la realización de un encuentro entre un amplio espectro de actores relacionados a la temática del VIH/SIDA para discutir distintos tópicos que permitan mejorar el desempeño y el rendimiento de este modelo.

\section{Conclusiones del comentador}

Aunque con limitaciones significativas, este modelo intenta poner en el tablero estrategias que hagan pensar acerca de un cambio copernicano en la historia natural de la epidemia del $\mathrm{VIH}$ en el mundo.

Ver glosario*

Joaquin Caporale [ Instituto de Efectividad Clínica y Sanitaria (IECS) Buenos Aires y Facultad de Ciencias Médicas de la Universidad Nacional de La Plata, Argentina. joaquincaporale@yahoo.com.anr ]

Caporale $\mathrm{J}$. El testeo universal en adultos del virus de la inmunodeficiencia y una terapia antirretroviral inmediata podría eliminar su transmisión y reducir costos. Evid. Actual. Práct. Ambul; 12(3): 101. Jul-Sep 2009. Comentado de: Granich R y col. Universal voluntary HIV testing with immediate antiretroviral therapy as a strategy for elimination of HIV transmission: a mathematical model. The Lancet 2009; $373: 48-57$. PMID: 19038438 